DOI: $10.14451 / 1.179 .125$

\title{
ОСОБЕННОСТИ БАНКОВСКОГО КРЕДИТОВАНИЯ ЮРИДИЧЕСКИХ ЛИЦ В СОВРЕМЕННЫХ УСЛОВИЯХ РОССИЙСКОЙ ЭКОНОМИКИ
}

\author{
(c) 2019 Славин Николай Сергеевич \\ кандидат экономических наук, доцент кафедры «Экономика транспорта» \\ Петербургский государственный университет путей сообщения Императора Александра I, \\ Россия, Санкт-Петербург \\ E-mail: slanspb@mail.ru
}

В статье рассмотрены современные тенденции развития банковского кредитования юридических лиц в России. Проанализирована динамика изменения объёмов кредитования российскими коммерческими банками юридических лиц в 2018 году и 2019 году. Проведён анализ подходов к оценке кредитного риска потенциального заёмщика.

Ключевые слова: коммерческий банк; экономика; кредит; кредитный риск; юридическое лицо; Россия.

Кредитование юридических лиц является чрезвычайно важным инструментом поддержания текущей ликвидности отечественных юридических лиц. Возможность получения дополнительного финансирования для реализации различных бизнес задач является одним из ключевых критериев конкурентоспособности российских компаний. Однако, в сложившихся условиях на отечественном рынке, доступность банковского кредита для юридических лиц, несмотря на некоторое смягчение монетарной политики Банка России, остается на невысоком уровне. На рис. 1 изображена динамика предоставленных кредитов юридическим лицам в 2019 году (по сентябрь 2019 г.).

Из данных рис. 1 видно, что объёмы кредитования с начала 2019 года увеличиваются. Данное обстоятельство обусловлено, как сезонным фактором, так и смягчением монетарной политики Центрального банка Российской Федерации в 2019 году. Так, Банк России снизил ключевую ставку с 7,75\% на начало 2019 года до 6,5\% по состоянию на 28.10.2019 года. Таким образом, цена фондированию для российских коммерче-

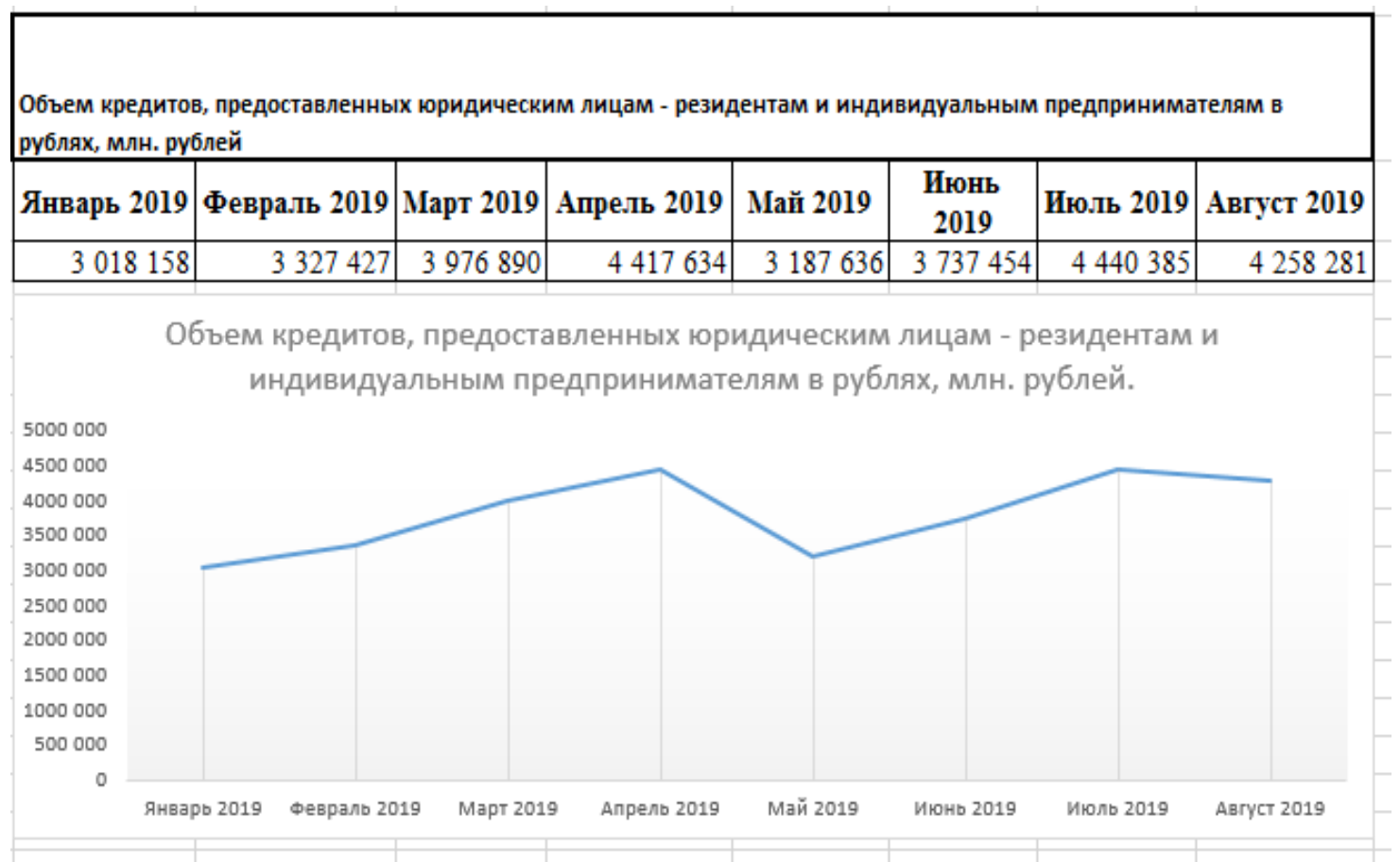

Рис.1. Объём кредитов, выданных юридическим лицам банковской системой РФ с января по август 2019 году (млн. руб.) [2] 


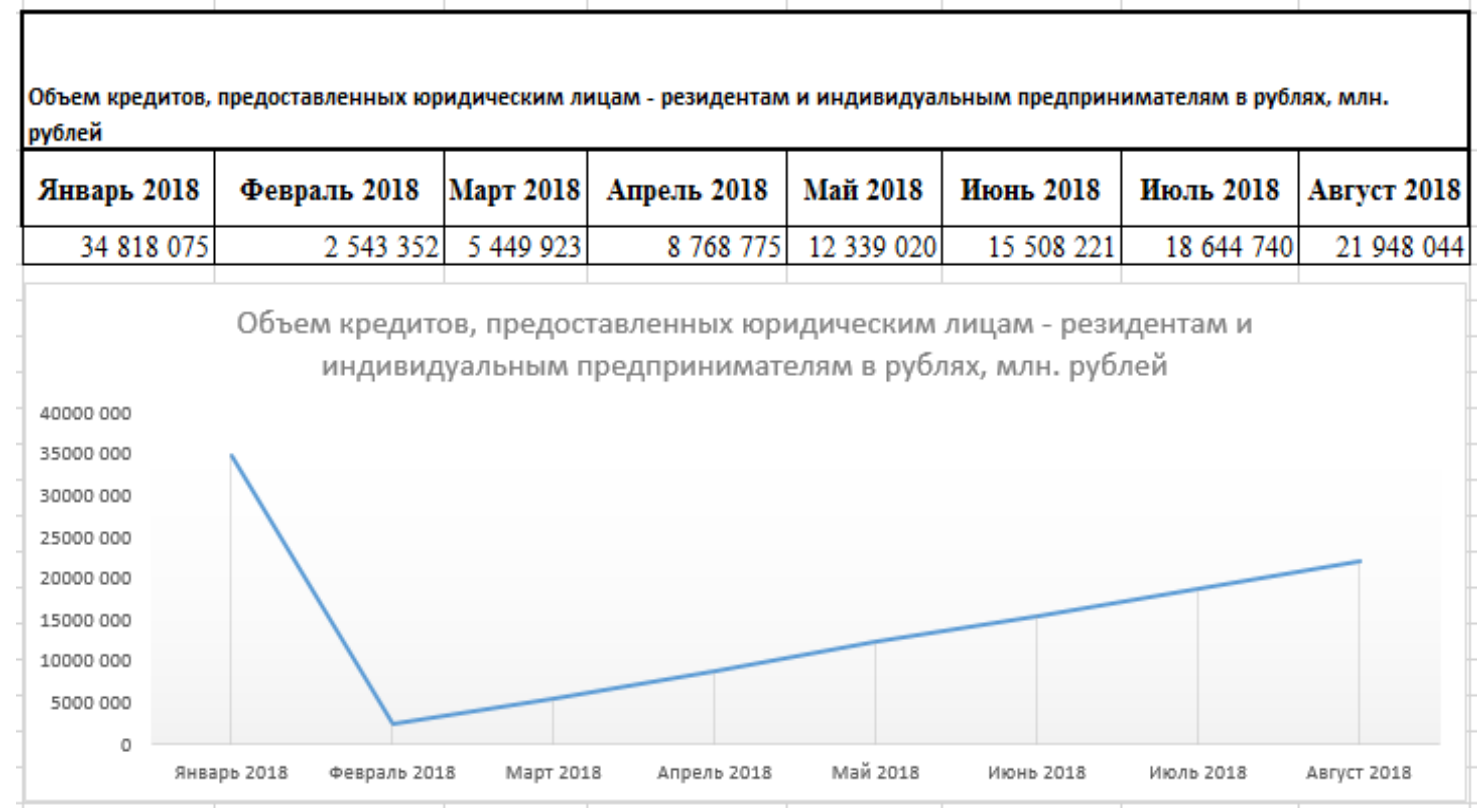

Рис.2. Объём кредитов, выданных юридическим лицам банковской системой РФ с января по август 2018 году (млн. руб.) [3]

ских банков, получаемая от Банка России стала ниже, что также, отчасти, способствует снижению процентных ставок по выдаваемым кредитам коммерческими банками.

На рис. 2 отражена динамика объёма выдач кредитов юридическим лицам российскими коммерческими банками за 8 месяцев 2018 года.

Исходя из данных рис. 1 и рис. 2 видно, что за 8 месяцев 2018 года объёмы кредитования российских юридических лиц были существенно выше нежели объёмы кредитования российскими коммерческими банками юридических лиц за аналогичный период 2019 года. Если за 9 месяцев 2019 года данный показатель составлял 30363865 млн. рублей, то за 9 месяцев 2018 года этот показатель был на уровне 120020150 млн. рублей. Таким образом, отталкиваясь от объёмов предоставленных кредитов российскими коммерческими банками юридическим лицам за 8 месяцев 2018 года и 8 месяцев 2019 года можно сделать вывод о снижении доступности банковского кредитования для юридических лиц. Данное обстоятельство, в основном, обусловлено ростом кредитного риска при кредитовании юридических лиц в 2019 году по сравнению с 2018 годом. Прогнозируемый рост ВВП России в 2019 году меньше, чем рост ВВП в 2018 году. Более того, фискальная нагрузка в 2019 году выросла за счёт роста НДС с 18\% до 20\%. Продолжается падения реально располага- емых доходов домохозяйств, что снижает потребительский спрос. Однако, уровень инфляции в 2019 году ниже, нежели в 2018 году, что может способствовать некоторому оживлению инвестиционной активности.

В сложившихся условиях отечественные коммерческие банки стараются занимать консервативную кредитную политику в области кредитования юридических лиц. Коммерческие банки смещают фокус кредитования в пользу предоставления краткосрочных кредитов бизнесу на цели финансирования оборотного капитала. Краткосрочные кредиты предоставляются преимущественно до года, что делает возможность прогнозирования возвратности инвестиций максимально приближённым к реальности. Более того, сокращается объём предоставления беззалоговых кредитов. Залог, в данном случаем является не только источником возможного погашения кредита, но и важным психологическим фактором воздействия на заёмщика, способствующим снижению кредитного риска. Однако, несмотря на наличие ликвидного залога коммерческие банки внимательно оценивают финансовую устойчивость потенциального заёмщика - юридического лица. Ниже приведены основные моменты, на что обращает внимание коммерческий банк при принятии решения о платежеспособности кредитуемого бизнеса:

- Анализ дебиторской задолженности на 
предмет выявления просроченной дебиторской задолженности;

- Анализ кредиторской задолженности на предмет выявления просроченной кредиторской задолженности;

- Анализ динамики выручки и прибыли;

- Расчёт показателей финансовой устойчивости и ликвидности организации;

- Анализ пула имеющихся контрактов с заказчиками на предмет выявления источников погашения кредита;

- Анализ степени диверсификации взаимодействия с контрагентами;

- Анализ репутационной составляющей организации.

Анализ всех вышеперечисленных моментов является чрезвычайно важным в современных условиях. Коммерческий банк, при принятии решения о возможности предоставления кредита юридическому лицу, должен убедиться в отсутствии негативных тенденций в бизнесе потенциального заёмщика, а также, убедиться в наличие источников погашения кредита. При этом, ликвидный залог является лишь дополнительной страховкой, а нет основным источником погашения кредита.

Учитывая вышеизложенное, необходимо отметить, что кредитование юридических лиц коммерческими банками в современных услови- ях в России сопряжено с детальной оценкой платежеспособности предполагаемого заёмщика и необходимостью предоставления ликвидного залогового обеспечения. При этом потенциальный заёмщик должен обладать безупречной репутацией и хорошей кредитной историей. Наличие подтверждённых источников погашения кредита (действующий контракт) всегда является дополнительным важным фактором снижения кредитного риска, что способствует увеличению вероятности получения юридическим лицом положительного решения по рассматриваемой кредитной заявке в коммерческом банке. Также, в связи с снижение горизонта планирования отечественной экономики пользуются большим спросом краткосрочные кредиты на финансирование текущих целей бизнеса. Инвестиционное финансирование рассматривается банками как высокорискованное по причине более низкой вероятности оценки кредитного риска на длительные промежутки времени. При этом, практика предоставления проектного финансирования со стороны коммерческих банков практически отсутствует по причине высокорискованности оценки возвратности кредита исходя из будущего денежного потока, корректная оценка которого, в сложившихся обстоятельствах практически отсутствует.

\section{Библиографический список}

1. «Анализ долговой нагрузки в отраслях российской экономики», № 29, Центральный Банк Российской Федерации, февраль 2018 года;

2. Сведения о размещённых и привлечённых средствах [Электронный ресурс]// Банк России - Режим доступа: http://www.cbr.ru/statistics/pdko/sors/ (дата обращения: 27.10.2019 г.);

3. Сведения о размещённых и привлечённых средствах (ретроспективная информация до 01.02.2019 г. [Электронный ресурс]// Банк России - Режим доступа: http://www.cbr.ru/statistics/pdko/sors/retro/ (дата обращения: 27.10.2019 г.). 